\title{
Problems of Teaching Organisation in Combined (Split) Classes in Rural Areas of the Republic of Serbia
}

\author{
Igor Leščešen ${ }^{A}$, Ljubica Ivanović Bibić ${ }^{A}$, Aleksandra Dragin ${ }^{A}$, Dario Balent ${ }^{A}$ \\ Received: May 2013 | Revised: June 2013 | Accepted: June 2013
}

\begin{abstract}
Due to negative demographic trends that primarily took hold of rural areas in the Republic of Serbia as early as at the end of the twentieth century - a decline in birth-rate and migrations from rural to urban areas, the question of ever growing number of combined classes and their organisation is being raised. Combined classes in schools do not represent a desirable model that should be aspired to in the organising of educational work in primary education. In fact it is a necessity and practical need in certain social rural areas. Combined classes are increasingly becoming a reality. Village schools make 60 percent of the total number of schools and are attended by only 8 percent of pupils. The larger number of grades a classroom teacher works with in a classroom, the more numerous teaching organisation problems there are. The Educational Strategy of the Republic of Serbia 2011-2120 says that small village schools should be saved since their number will increase in the coming years considering demographic trends. This paper depicts main didactic problems that occur in the process of simultaneous work with students of different ages, in the same room, by one class teacher, as well as the possibility of their solution. Methods used in this paper include theoretical analysis of the existing literature as well as conversations with primary school teachers who teach combined classes.
\end{abstract}

Key words: teaching, combined classes, primary school, class teacher, rural area, Serbia

\section{Introduction}

The organisation of educational work in combined classes is complex, and its study elaborate. Despite the noticeable trend towards the increase of combined classes in Serbia, they receive little attention in the contemporary pedagogical and methodical literature. Because of the need to fulfill curricula and teaching plans, as well as the total educational work, and confronted with lack of literature and precise instructions, schools with combined classes have adjusted to time, conditions, and tasks set before them. Yet this kind of work retained a lot of old, traditional, as well as a lot of irrational and unproductive (Radevic, 2008). Weaknesses and limitations of the existing organisation of educational work in combined classes are also the reflection of legal solutions, that is to say of strict nor- mative school regulations, irrespective of the place a school is situated in (Radevic, 2008).

Even though the problematics of work in combined classes predominantly refer to lower grades (from first to forth), if negative demographic trends continue, it is only a question of time when this problem will occur in higher grades of primary schools.

\section{Former studies on educational work problems in combined classes}

There has been a small number of publications on the topic of educational work problems in combined classes; they were mostly published immediately after the Second World War, that certainly is not enough (Radevic, 2008). The trend towards the increase of number

\footnotetext{
A Department of Geography, Tourism and Hotel management, Faculty of Science, University of Novi Sad, Trg Dositeja Obradovića 3, 21000 Novi Sad, Serbia; igorlescesen@yahoo.com
} 
of combination-class schools (schools with separate departments where teachers teach combined classes) has already been brought to attention, thus this problematics represent a new area for studying didactic and methodological literature. In his book Working In an Undivided Primary School And In a Combined Class Vukovic (1951) brought out the concept based on data and experience from the long tradition of educational practice in combined classes and this work reflects to what extent our pedagogical theory and educational practice were developed at that time. However, many ideas brought out in his book are actual even today. In the mentioned book Vukovic also published several papers on this topic. In 1992, Trnavac expanded and published this bibliography in his book Small Village Schools. Thanks to this Vukovic's book the material basis was improved, the expansion of educational technique that penetrated combined classes faster and faster occurred and there was also a positive change considering teachers' qualifications in favour of academy and university-level degrees.

In 1981, Stevanovic and Djordjevic published a book in this field entitled Teaching Organisation In Com bined Classes (Radevic 2008). It was already next year that Bukovic and Radosevic published a paper named 'The Organisation And Realisation of Educational Work In Combined Classes of Primary Schools.' It should be pointed out that more attention has been paid to this topic since 2003. Papers that also largely contributed and gave importance to this topic are: 'Work Rationalisation in Combined Classes' (Spijunovic 2003), 'Open Problems of Work Organisation in Combined Classes' (Milosevic, 2003) and 'How Teachers Perceive Pupils' Activities In Combined Classes' (Marinkovic, 2007).

\section{Meeting of a teacher with a combined class}

At teacher-training faculties little attention is paid to practical work with students, very little to the problems of everyday teaching obligations such as keeping administration (attendance register) and almost no attention is paid to combined classes (Milosevic, 2003). Future class teachers and subject teachers are trained for this type of teaching: one grade - one class. A combined class with all its specificities is left to chance, which has a disastrous effect on results of educational work (Milosevic, 2003). When a graduated teacher finds himself in a situation to work in a school where teaching is organised in combined classes, he meets a range of practical problems that his professional education didn't prepare nor train him to solve. Some of these problems are: how to make an annual global curriculum, how to conceptualise a monthly curriculum based on the annual curriculum, how to write the first preparation for work in a combined class, how to register the first class in the attendance register and many more.

Then a teacher's didactic and methodological qualifications, his motivation, his desire to work and pass his knowledge on to his students come on the scene. A combined class gives a teacher a wide range of possibilities to organise a teaching process, that could be more advantageous than possibilities he would have in a homogenous class. However there are also problems that represent the obstacle to the realisation of teaching contents. Advantages and disadvantages of this type of teaching will be further discussed in the following chapters.

\section{Work organisation in combined classes}

Work in a combined class has at least three specificities: a teacher simultaneously works with pupils from two or more grades, pupils of different ages are grouped within one classroom, learning process takes place in the context of village schools (Marinkovic, 2007). It is known that before the beginning of a school year a teacher should write preparations for all lessons. However, writing preparations for lessons in combined classes is a particularly open question since this problem has not yet drawn necessary attention in pedagogical theory and practice. Two completely physically separate written preparations for one class, that should be combined immediately during the class have disastrous effects on students' cognitive process because a teacher is not capable to follow two preparations and to naturally create unique lesson course at the same time. In this case whole teaching process is reduced to bad improvisation.

Classes can be differently combined:

- Combined classes made of students from two grade levels. This model includes two possibilities: combined classes of closer grades (first and second, third and fourth) and combined classes of further grades (first and third, second and fourth);

- Combined classes made of students from three grade levels;

- Combined classes made of students from four grade levels.

While forming classes primary schools must apply Article 27 of the Law on Primary Schools which states that a combined class made of pupils from two grade levels mustn't have more than twenty pupils, while a combined class made of pupils from three or four grade levels mustn't have more than fifteen pupils. However experience has shown that number of pupils in such classes is often one digit.

Organisation of educational work in combined classes is one of the most complex and most sensitive 
issues in didactic theory and practice. Organisation of educational work in combined classes implies the way of working that provides the accomplishment of optimal results in the realisation of primary education aims and tasks. Organisational problem defined in such a way can be considered from two perspectives: form the perspective of outer and from the perspective of inner organisation.

Outer organisation of educational work in a combined class includes everything that is out of the sphere of direct teacher's influence (space, equipment, instructional means and technical facilities, curriculum and teaching plan, legal regulations, school calendar, number of pupils in a classroom, textbooks and reference books). Contrary to outer organisation the inner organisation of educational work in a combined classroom includes everything that is, more or less, in the sphere of direct teacher's influence (class organisation, planning of lessons, lesson preparations, seating arrangements for pupils, use of instructional means and so on.) In fact inner organisation represents the organisation of the very course of educational process.

Both these dimensions of organisation, outer and inner, influence each other and intertwine with each other, and success of educational work mostly depends on their unity (Radevic, 2008).

Central question of this study is the question of type and quality of pupils' activities: in their independent work, in direct work with a teacher, in mutual activities of younger and older pupils.

\section{Dominant pupils' activities during independent work}

A teacher has numerous activities at his disposal: to engage one grade while he works directly with the other. Activities for independent work in a geography class for instance are: filling of workbooks, answering teacher's questions in written form, pupils devise questions independently, performing practical activities - sketching, making relief models, filling blank maps, independent text reading, solving problem situations, giving examples form everyday life considering the given teaching unit, deducing principles, truths or rules based on large number of examples, making of one's own review of teaching material.

The offered activities enable us to see the context in which independent pupils' work takes place. However we must bare this in mind: even when pupils read a text we don't know whether they read it only informatively or they single out the most important parts of it. We have similar situation when they are filing in their workbooks. The quality of books has an important role here. Teacher must phrase questions in a way that demands correlation with previously attained knowledge, its usage and problems solving.

\section{Dominant pupils' activities during direct work with a teacher}

When direct work with pupils is considered there are different methods. Research has shown that teachers with higher education qualifications put their pupils in problem situations more often. In the same way teachers often develop discussions, which imply dialogs between teachers and students in which teachers ask questions and students answer them. The lecturing method is mainly used by teachers who don't have too much experience in work with combined classes. On the other hand teachers with longer experience in combined classes less prefer lecturing method as a way of work with pupils and rather use individual work with pupils and putting pupils in problem situations (Marinkovic, 2007).

\section{Mutual activities of younger and older pupils in a class}

Presence of pupils of diverse ages in one class is reality in combined classes. A teacher can use this situation in classes intended for revision, practice, knowledge systematisation and reinforcement, as well as in classes intended for teaching new lessons. There are advantages as well as disadvantages (problems) in mutual work of older and younger pupils.

Table 1. Advantages and problems of mutual activities of older and younger pupils

\begin{tabular}{|l|l|}
\hline Advantages & Problems \\
\hline - Pupils from higher grades revise old learning material & - Diminished or insufficient participation of younger \\
- Older pupils help younger pupils to acquire and reinforce new & Pupils \\
- Oearning material & $\begin{array}{l}\text { Older pupils imitate a teacher (strictness, } \\
\text { intolerance) }\end{array}$ \\
- Oder pupils represent an ideal, a model to younger pupils. & $\begin{array}{l}\text { Younger pupils question older pupils' authority } \\
\text { - Younterest are awaken in younger pupils }\end{array}$ \\
- Younger pupils learn from older ones & $\begin{array}{l}\text { - Older pupils wrongly teach younger ones } \\
\text { teacher because there is no fear of wrong answer }\end{array}$ \\
Younger pupils adjust more easily in this way & $\begin{array}{l}\text { There are no problem situations, older pupils lecture } \\
\text { younger pupils }\end{array}$ \\
\hline
\end{tabular}

Source: Marinkovic, 2007. 


\section{Advantages and disadvantages of work in combined classes}

The advantages of work in combined classes are big and offer huge possibilities for teachers' and pupils' creativity. It is highly significant that pupils from higher grades are often in a situation to be reminded about the contents they learned in previous years and to revise them, and pupils from lower grades are in a situation to hear and memorise numerous facts and notions that pupils form higher grades use. A teacher in a combined class is firstly an adviser, an associate and work organiser and least of all someone who passes knowledge on to pupils. Pupils are actively involved in the process of acquiring knowledge and skills development, and a teacher only organises and directs educational work.

The advantages of work in combined classes are:

- Since a teacher works with a small number of pupils the need for individual work and the individualisation of teachingis emphasised, which creates conditions for esteem and respect of differences between pupils, for maximal development of their abilities, for advancement according to individual pace and inclinations.

- A combined class is convenient and stimulative environment for the development of pupils' independence and creativity.

- Individual pupils' work requires faster change to multimedia teaching system and its modernisation.

- In such working circumstances pupils are enabled for self-education (auto didacticism).

- More often revision and firmer connection of teaching contents in one whole are provided.

- Pupils from lower grades are in the situation to spontaneously learn numerous facts and terms that pupils from higher grades use and older grades are in the situation to be reminded about contents they learned in previous years and to revise them.

- Small number of pupils makes the control of their independent work quick and efficient.

- A combined class is convenient environment for steadier and more natural course in the process of pupils' socialisation.

- While in a single-grade class a teacher is most often the only person who passes knowledge on to pupils, his role in a combined class is to organise work, to advise and cooperate. The focus of his activity is to organise educational work in such a way that pupils are active in the process of acquiring knowledge and skills development.

The weaknesses of work in combined classes are ascribed to material sphere on the one and to the mere organisation of educational work on the other side. Material and technical weaknesses can be easily elim- inated by outer intervention of milieu a school is situated in, and weaknesses in organisation of educational work can be eliminated by an organised approach in adopting applicable pedagogical solutions, by more flexible legal regulations, by respecting conditions a combined class works in (Videnovic, 2008).

Disadvantages of work in combined classes are:

- Complex class organisation, especially in cases when a teacher simultaneously works with several grades, that is when he simultaneously realises two, three or even four curricula.

- Inflexible work organisation because work in combined classes follows the same principles that are applied in schools which have a thousand or more pupils.

- Lack of time for direct work of a teacher and pupils from certain grades.

- Often changes of teachers.

- Insufficient teacher's qualifications for work in a combined class

- Insufficiently elaborate system for professional teachers development (seminars, mock classes and alike)

- Teachers'isolation in terms of difficult, insufficient and inadequate cooperation with parent school and a milieu a school is situated in.

- Lack of appropriate methodological literature for work in combined classes.

- Schools are insufficiently equipped with teaching aids and technical appliances.

- Conditions in which pupils live and learn (Radevic, 2008).

\section{The improvement of work in combined classes}

In order to prevent further repetition of uniformity of curriculum and teaching plan as a serious obstacle to pedagogical efficiency of teaching, it is essential to use it more flexibly. Namely more contemporary solutions should be found in terms of curriculum individualisation. Making individual curricula, adjusted to students' abilities would decrease pupils' aversion and increase their desire for knowledge.

Certain ideas on integrated teaching could also find their place in teaching in combined classes. That is to say that teaching contents could be integrated only in two large entireties (humanities and natural science) and teachers would plan teaching according to needs and progress tempo of each pupil. Same curriculum should be accepted in all schools provided that flexibility of its application should be allowed in combined classes depending on the number of pupils in a class, or a grade, on their abilities, surrounding conditions and other factors. 
A teacher in a combined class should have the right and freedom to deviate from prescribed curriculum to a certain extent in concrete circumstances and according to defined criteria, that is to say that a teacher of a combined class should have certain degree of pedagogical autonomy in the conceptualisation of concrete organisational solutions. Spijunovic (2003) believes that certain freedom given to a teacher would not have damaging effects on total work results, as many think, on the contrary it would be more encouraging than curriculum uniformity that suffocates and prevents every initiative. Giving such freedom primarily assumes teachers' expertise, their creativity, but also their motivation and responsibility for accomplished results.

Application of multimedia presentations also gave positive results in teaching. It was shown that thanks to multimedia presentations (animated teaching contents on a computer) slow learners progress much faster and much easier. Monotony and formalism are being avoided and possibility for visual representation of abstract ideas is being opened up. Change of diverse activities and application of modern technology contribute to better class dynamics and by that to activation of all pupils (Padevic, 2005).

Indirect types of work should become prominent in combined classes, when a teacher organises independent work for students and from beginning to the end of their activities pupils endeavour to perform given tasks (learning new teaching material, revision, knowledge reinforcement and alike). During that time a teacher tends to unobtrusively withdraw himself, to move himself from the center of attention. Indirect forms of work include:

- individual form of work,

- working in couples and

- group work.

Individual work implies working with bigger number of pupils provided that pupils perform certain tasks independently. Working in couples (in tandems) makes the transition from individual towards group work. The advantage of this type of work is that pupils compare themselves with each other, and comparison has an encouraging effect on them. On the other hand group (collective) work can be used in all stages of teaching. Group work creates the possibility for solving problems in a group and presenting results to the rest of the class (Romelic, 2004).

When teaching contents in higher grades are considered there is the possibility of exemplary teaching in certain subjects, especially in the sixth, seventh and eighth grade. In geography classes for instance when teaching regional geography a teacher can do one region or one state and pupils can do next unit in the same way. Since the contents on regional geography are in question, teaching of units from sixth grade can be applied to the seventh grade as well, because pupils only have to stick to geographic order. This way of teaching is particularly convenient because it allows individual or group work of pupils (depending on the number of pupils in a class). In that way their cognitive abilities develop, they perceive logic and sequence of things, they independently choose contents they consider important, which influence the independence in work.

A problem occurs when choosing teaching methods. Each of them is appropriate for work in homogenous classes, but in combined classes they show their shortcomings. The application of these methods in combined classes requires good methodical training of teachers. While a teacher orally represents teaching material to one grade, he could distract pupils from other grade and draw their attention from the realisation of their tasks or their attention could be attracted by the topic a teacher is talking about. However this method could also serve pupils from higher grades to revise teaching material. Besides positive effect on cognitive development of pupils the conversation method could also have negative influence, similar to the previous method. The textual method could be well-applied in combined classes, but pupils can be distracted by presentations of pupils from other grades.

It has already been pointed out that the realisation of teaching and the choice of teaching methods in combined classes require good psychological, didactic and methodological training of a teacher as well as high degree of creativity and also of adaptability. Preparation of teachers for work with two or more grades is specific. It has to be functional. A teacher should stick to the following instructions:

- While he works directly with one grade, other pupils should work indirectly;

- Tasks for individual work must be interesting, comprehensive, of adequate scope and difficulty, in accordance with pupils' abilities;

- Before transition to direct work a teacher should check what is done during individual work and how it is done;

- Pupils could work together at the end of the class.

Working in combined classes requires faster transition to multimedia approach to teaching and its modernisation. Use of computers in classes contributes to efficiency, rationalisation, better quality of teaching, greater interest of students and better durability of acquired knowledge. Computers have proper purpose in combined classes. The use of computers create even better conditions for esteem and respect of differences between pupils, for maximal development of their abilities, for advancement according to individual pace and inclinations. A teacher in a combined class 
is primarily work organiser, an adviser and associate. A combined class is convenient and stimulative environment for the development of pupils' independence and creativity, it enables pupils for self-education, and computer encourages that even more.

\section{Conclusion}

Combined classes are our reality. If current demographic trends continue we can expect continuous increase of number of schools with combined classes. From that very reason it is necessary to give due attention to this problematics in theoretic and practical analysis.

Opinions on the success of pupils that attend combined classes are divided. Some psychologists believe that pupils in such classes accomplish significantly less than pupils in single-grade classes. Other group of psychologists claim that these pupils do not lag, on the contrary they even outperform pupils from regular classes in their success.

Teaching combined classes is one of the most difficult teaching tasks. That is why teachers should be educated at the initial level and their further professional development for working in combined classes should be planned and directed especially in the following areas: designing problem situations in teaching, the organisation of mutual activities of older and younger pupils, creating good learning situations in the course of direct and indirect work.

However, effects of teaching in combined classes aren't necessarily below success level of single-grade classes. That is to say that by using appropriate didactic and methodological solutions - more flexible approach to the organisation of teaching in combined classes and especially by using more flexible approach to the application of curriculum, it is even possible to turn something that was always considered to be an inevitable disadvantage into an advantage. Distance learning is becoming reality. Then why wouldn't combined classes where teacher is directly present have good results?

\section{Acknowledgments}

This paper was created through the research and project preparation of two postgraduate master students Igor
Lescesen and Dario Balent in subject School buildings and teaching resources in teaching geography under the tutorship of professors Phd Aleksandra Dragin and Phd Ljubica Ivanovic Bibic.

The authors owe special gratitude to geography teachers who passed on to them their experience in working with combined classes gained through years in rural areas all across Serbia.

\section{References}

Educational Strategy in Serbia until 2020, Ministry of Education, Science and Technological Development of the Republic of Serbia, Belgrade, 2011.

Ivic, I., Pesikan, A. 2001. Active Learning 2, handbook. UNICEF and Institute for Psychology, Belgrade.

Lazarevic, Z. 1998. Methodology - the Scientific and Teaching Discipline, Teacher Training Faculty, Jagodina.

Lekic, D. 1968. Methodology of Pedagogic and Instructional Work in Schools, Mlado pokolenje, Belgrade.

Marinkovic, S. 2004. Children's Rights And a Textbook, Institute for Textbooks and Teaching Resources, Belgrade.

Marinkovic, S. 2007. How Teachers Perceive Pupils Activities In Combined Classes, Norma, Belgrade.

Milosevic, S. 2003. Open Problems of Work Organisation in Combined Classes, Pedagoska stvarnost 49, Belgrade.

Prodanovic, Lj., Lunginovic, D. 1985. Teaching Organisation in Combined Classes, Decije novine, Gornji Milanovac.

Radevic, S. 2008. More Flexible Application of Curricula in Combined Classes, Norma, Belgrade.

Romelic, J. 2004. Methods of Teaching Geography, Faculty of Sciences, Novi Sad.

Rudic, V. 1991. Methods of Teaching Geography, Naucna knjiga, Belgrade.

Spijunovic, K. 2003. The Rationalisation of Work in Combined Classes, Teacher Training Faculty, Uzice.

Vukovic, R., Radosevic, B. 1982. The Organisation And Realisation of Educational Work In Combined Classes of Primary Schools, Republic Institute for Educational Development, Titograd. 